\title{
Website Pemesanan Karangan Bunga Dekoratif dengan Fasilitas Kustomisasi Rangkaian
}

\author{
Ivan Pramono ${ }^{1}$, Eric Sugiharto ${ }^{1}$ \\ ${ }^{1}$ Departemen Sistem Informasi, Sekolah Tinggi Teknik Surabaya \\ Email : ivanprambros@gmail.com, ericsugiharto@stts.edu
}

\begin{abstract}
Abstrak-Teknologi yang semakin berkembang pesat dari hari ke hari memberikan dampak yang besar bagi dunia. Bahkan teknologi sangat berpengaruh di bidang bisnis. Banyaknya usaha-usaha di bidang online yang bermunculan saat ini, membuat cara berpikir masyarakat jaman sekarang yang dibuat jauh lebih praktis. Berbelanja tanpa harus pergi ke mall atau toko dan menghabiskan waktu yang banyak untuk antri, maka toko di bidang online seperti website mulai bermunculan saat ini. Inilah salah satu tujuan pembuatan website toko bunga ini. Selain memberikan kenyamanan bagi pelanggan, juga memberi keuntungan pada pemilik toko untuk dapat mengatur toko nya menjadi lebih berkembang. Selain menjual bunga, website ini juga memiliki fitur khusus yaitu kustomisasi rangkaian bunga. Tidak seperti website lain, pelanggan dapat melakukan kustomisasi rangakaian bunga secara online sesuai keinginannya. Website ini juga memiliki fitur dari sisi pemilik toko untuk mengatur jalannya usaha. Dari hasil uji coba website toko bunga yang sudah diberikan kepada beberapa responden sebagai pelanggan dan sebagai pemilik toko. Dapat disimpulkan bahwa pemilik toko merasa sangat terbantu dengan adanya website ini untuk mengatur jalannya usaha mereka secara praktis. Dari sisi pelanggan, pelanggan dapat melakukan kustomisasi rangkaian sesuai keinginan mereka dengan mudah. Selain itu pelanggan juga dimudahkan dengan cara transaksi yang terdapat pada website toko bunga ini.
\end{abstract}

Kata Kunci-Bunga, Kustomisasi, Praktis, Website

\section{Pendahuluan}

$\mathrm{P}$ embuatan website Fiore Fragrance ini diharapkan dapat membangun sebuah website yang bertujuan untuk tempat penjualan bunga di bidang online secara praktis. Terlebih website ini dapat memberikan kemudahan dalam melakukan kustomisasi bunga secara real. Selain website yang dibuat guna untuk penjualan bunga kepada pelanggan, website ini juga berguna bagi pemilik usaha/toko yang ingin menjalankan usaha nya secara online atau berbasis website. Dengan kemudahan untuk dapat mengatur isi dari website, memantau penjualan yang terjadi di dalam website dan melihat setiap laporan yang sedang terjadi di dalam website tersebut.

\section{RUANG LINGKUP}

Pada bagian front-end fitur-fitur yang ada pada website dapat diakses oleh pengguna tanpa harus melakukan proses register, dan login. Tetapi untuk pemesanan dapat diakses setelah proses login. Setelah login, maka pelanggan akan dipindahkan pada halaman utama yang berisikan menu-menu pilihan dan gambar jenis-jenis produk yang ada. Pada bagian back-end admin harus melakukan login dahulu untuk dapat mengakses data yang ada pada website, setup, dan melihat laporan website.

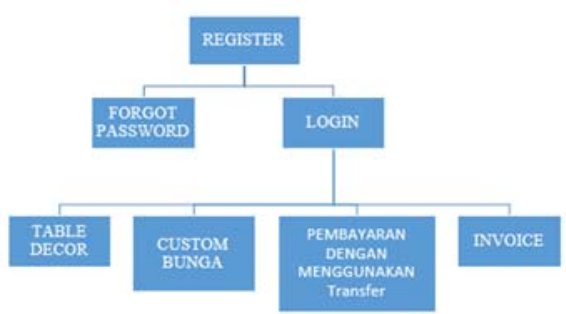

Gambar. 1. Ruang lingkup Frontend Website Fiore Fragrance

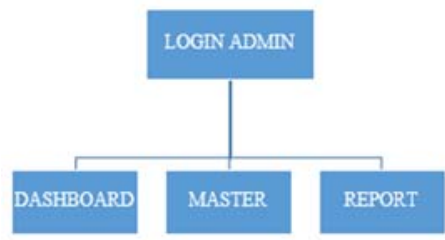

Gambar. 2. Ruang lingkup Backend Website Fiore Fragrance

\section{TEORI DASAR}

Berikut ini akan dijelaskan mengenai teori-teori dasar yang digunakan dalam pembuatan website ini. Teori-teori tersebut terdiri dari teori untuk tampilan website dan teori yang digunakan dalam pemograman.

\section{A. HTML5}

HTML5 adalah sebuah bahasa markah untuk menstrukturkan dan menampilkan isi dari world wide web, sebuah teknologi inti dari Internet. HTML5 adalah revisi kelima dari HTML (yang pertama kali diciptakan pada tahun 1990 dan versi keempatnya, HTML4, pada tahun 1997) dan hingga bulan Juni 2011 masih dalam pengembangan. Tujuan utama dari pengembangan HTML5 adalah untuk memperbaiki teknologi HTML agar dapat mendukung teknologi multimedia terbaru, mudah dibaca oleh manusia dan juga mudah dibaca oleh mesin. HTML5 memiliki 
berbagai fitur yang terbilang cukup berguna bagi para programmer.

Fitur-fitur yang terdapat dalam HTML5 dan digunakan dalam pembuatan website toko bunga ini diantaranya yaitu Canvas Elemen. Dengan tag < canvas $>$, area tersebut dapat digunakan untuk menggambar grafik secara dinamis menggunakan javascript. Misalnya seperti shape lingkaran, garis diagonal, hingga grafik 3 dimensi. Dan masih banyak fitur baru lainnya yang disediakan oleh HTML5 seperti kemampuan untuk Drag and Drop, Geolocation, Offline Web Application, Text Api, Datagrid, Cross Document Mesaging, SVG Elemen dan lainnya. Teori HTML5 ini digunakan di dalam pembuatan website ini yaitu untuk membuat kustomisasi yang ada pada website ini.

\section{B. Laravel}

Pembuatan dari Website toko bunga ini menggunakan framework Laravel untuk memudahkan proses perancangan website untuk toko bunga. Laravel adalah sebuah framework PHP yang dirilis di bawah lisensi MIT, dibangun dengan konsep MVC (Model View Controller). Laravel adalah pengembangan website berbasis MVP yang ditulis dalam PHP yang dirancang untuk meningkatkan kualitas perangkat lunak dengan mengurangi biaya pengembangan awal dan biaya pemeliharaan, dan untuk meningkatkan pengalaman bekerja dengan aplikasi dengan menyediakan sintaks yang ekspresif, jelas, dan menghemat waktu.

Di dalam Laravel terdapat banyak fitur khusus diantaranya blade, eloquent, authentication, facade dan migration. Blade merupakan template yang telah disediakan oleh Laravel membantu dalam mendesain tampilan web yang sedang dibuat. File blade diberi nama dengan tambahan blade.php pada ekstensinya dan disimpan di folder resources/views. Untuk menampikan blade dapat digunakan syntax return view('nama_blade') dan juga untuk memakai blade sebagai tambahan pada sebuah desain halaman web menggunakan syntax@include('nama_blade').

Eloquent merupakan fitur yang disediakan laravel untuk mengakses database dari program yang dibuat. Untuk menggunakan fitur eloquent terlebih dahulu harus memiliki model. Untuk membuat model dapat menggunakan syntax php artisan make:model User - migration pada command prompt di folder project anda. Laravel memiliki cukup banyak fitur-fitur yang ada di dalamnya. Beberapa fitur yang digunakan di dalam pembuatan website ini adalah fitur eloquent ORM. Fitur ini digunakan sebagai class untuk mengakses tabel pada database yang ada supaya dapat diakses lebih mudah ketika ingin digunakan. Selain itu juga ada fitur authentication yang digunakan sebagai sistem keamanan suatu website tersebut.

\section{CSS Bootstrap}

Bootstrap adalah sebuah alat bantu untuk membuat sebuah tampilan halaman website secara responsive. Artinya, tampilan web yang dibuat oleh bootstrap akan menyesuaikan ukuran layar dari browser yang digunakan baik di desktop, tablet maupun mobile device. Fitur ini bisa diaktifkan ataupun dinonaktifkan sesuai dengan keinginan programmer, sehingga programmer bisa membuat web untuk tampilan desktop saja dan apabila dibuka oleh mobile browser maka tampilan dari web tersebut tidak bisa beradaptasi sesuai layar. Dengan bootstrap, programmer juga bisa membangun web dinamis maupun statis.

- Kelebihan Bootstrap:

1. Waktu pembuatan yang lebih cepat

2. Template yang menggunakan Bootstrap lebih rapi

3. Template yang menggunakan Bootstrap lebih ringan

4. Responsive dan tidak responsive

5. Banyak template bootstrap gratis

6. Twitter Bootstrap juga memiliki code yang cukup mudah untuk dipelajari.

- Kekurangan Bootstrap:

1. Minim gambar karena menggunakan CSS3

2. Belum mampu memberikan tampilan yang sesuai di semua web browser

3. Membuat pengguna bootstrap menjadi kurang kreatif karena terpaku dengan coding yang dikembangkan oleh developer.

4. Banyak source atau yang tidak dipakai karena tidak sesuai keinginan pengguna.

\section{PHP}

PHP (Hypertext Preprocessor) merupakan bahasa pemograman yang bekerja pada sisi server yang dapat disisipkan ke dalam HTML. Bahasa pemograman PHP merupakan bahasa yang khusus untuk pengembangan website karena PHP merupakan bahasa yang relatif mudah digunakan dan bersifat gratis, sehingga bahasa pemograman banyak digandrungi oleh banyak pengembang website. Maka dari itu tak jarang banyak ahli program yang menggunakan PHP untuk membuat website.

\section{E. JavaScript dan jQuery}

JQuery merupakan pustaka untuk memanipulasi DOM (Document Object Model). DOM adalah struktur-pohon representasi dari semua elemen yang terdapat dalam sebuah halaman Web, dan JQuery menyederhanakan sintaks untuk mencari, menyeleksi, dan memanipulasi elemen-elemen DOM tersebut. Sebagai contoh, jQuery dapat digunakan untuk mencari elemen dalam dokumen dengan properti tertentu, mengubah satu atau lebih atribut tersebut, atau membuatnya merespon sebuah event. JQuery juga menyediakan sebuah paradigma untuk penanganan event yang diluar pemilihan dan manipulasi elemen dasar DOM. Event assignment dan event callback function dapat dilakukan dengan hanya satu langkah atau satu baris kode. JQuery juga bertujuan menggabungkan fungsional JavaScript yang sering digunakan.

\section{F. MySQL}

MySQL adalah sebuah implementasi dari sistem manajemen basisdata relasional (RDBMS) yang didistribusikan secara gratis. Setiap pengguna dapat secara bebas menggunakan MySQL, namun dengan batasan perangkat lunak tersebut tidak boleh dijadikan produk turunan yang bersifat komersial. MySQL sebenarnya merupakan turunan salah satu konsep utama dalam basisdata yang telah ada sebelumnya; SQL (Structured Query 
Language). SQL adalah sebuah konsep pengoperasian basis data, terutama untuk pemilihan atau seleksi dan pemasukan data, yang memungkinkan pengoperasian data dikerjakan dengan mudah secara otomatis.

\section{G. FabricJS Library}

FabricJS merupakan library yang digunakan di dalam HTML5. FabricJS sendiri digunakan untuk pembuatan objekobjek dasar seperti menggambar kotak, persegi panjang, ataupun lingkaran. Selain itu juga dapat import gambar untuk dijadikan objek di dalam canvas. Di dalam pembuatan website toko bunga ini, FabricJS digunakan untuk pembuatan custom bunga secara realtime dengan menggunakan objek bunga berbentuk $2 \mathrm{D}$.

\section{Alur KerJa Website}

Berikut akan dijelaskan alur kerja dari website Fiore Fragrance dari sisi pelanggan dari awal pertama kali register hingga sampai kepada penerimaan barang. Serta akan dijelaskan alur kerja website dari sisi admin guna mengelola data website dan transaksi yang ada.

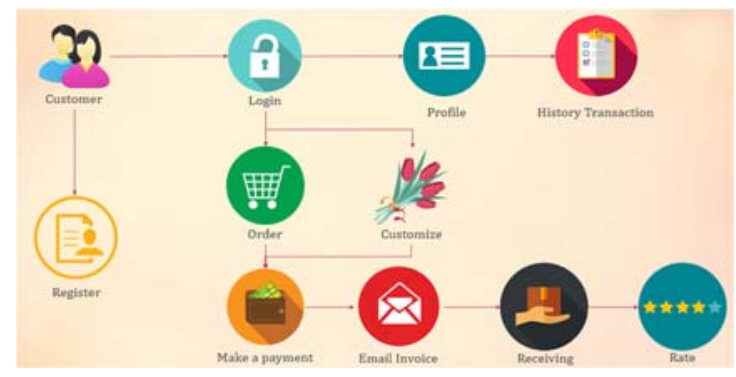

Gambar. 3. Alur Kerja Website dari sisi Pelanggan

Pelanggan harus melakukan registrasi dan login terlebih dahulu untuk dapat memesan bunga atau melakukan kustomisasi. Setelah pelanggan login, pelanggan dapat mengubah informasi pribadi pada halaman profil milik pelanggan. Pelanggan juga dapat melihat histori transaksi yang sudah pernah dilakukan oleh pelanggan. Pelanggan dapat membeli produk dari barang yang ada di dalam halaman produk atau melakukan kustomisasi bunga di dalam halaman kustom. Setelah pelanggan selesai memesan barang yang diinginkan, pelanggan dapat melakukan pembayaran di dalam halaman cart. Disini pelanggan dapat melihat dan membatalkan pesanan-pesanan yang sudah dipesan. Pelanggan harus memilih metode pengiriman yang ingin dilakukan. Mengambil sendiri di toko atau meminta layanan pengiriman oleh kurir. Setelah itu pelanggan harus mengupload bukti pembayaran berupa gambar yang akan diterima oleh admin. Pelanggan menunggu konfirmasi dari admin dan akan menerima email invoice dari admin jika pembayaran sudah dikonfirmasi oleh admin. Setelah itu pelanggan menerima barang dan dapat memberikan rating untuk produk yang dibeli pada website.

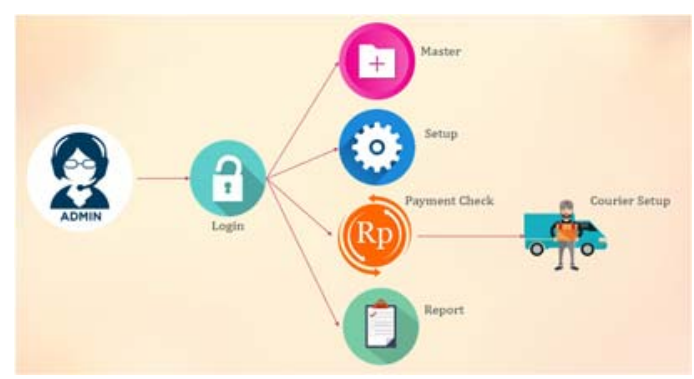

Gambar. 4. Alur Kerja Website dari sisi Admin

Dari sisi Admin, admin dapat melakukan perubahan dan penambahan data website. Disini admin dapat melakukan pengaturan diskon dan biaya pengiriman pada halaman setup. Admin melakukan cek pembayaran pelanggan di dalam halaman cek pembayaran. Disana admin mengecek apakah bukti transfer yang diupload oleh pelanggan sudah sesuai. Admin berhak membatalkan pembayaran jika ternyata tidak sesuai dan dapat menyertakan alasan penolakan yang nantinya akan diterima oleh pelanggan melalui email. Setelah admin mengkonfirmasi pembayarannya, jika pelanggan memilih metode pengiriman yang dilakukan oleh kurir maka admin akan mengatur pengiriman tersebut di dalam halaman atur pengiriman. Admin juga mengatur pengiriman yang sudah selesai dilakukan dan dapat mengupload surat jalan pengiriman ke dalam website sebagai bukti. Admin juga dapat melihat laporan penjualan di dalam website yang nantinya laporan tersebut akan dikirimkan melalui email toko.

\section{Fitur Website}

Terdapat fitur utama pada website Fiore Fragrance ini yang akan menunjang proses penggunaan website ini dengan baik.

\section{A. Fitur Penambahan Admin}

Jika pemilik ingin menambahkan user untuk admin, maka tersedia di bagian back-end untuk menambahkan admin baru, agar dapat memiliki wewenang dalam mengatur website ini.

\section{B. Fitur Penambahan Membership}

Pelanggan yang pertama kali membuka website tersebut, jika ingin melakukan pemesanan harus terlebih dahulu mendaftarkan diri menjadi membership untuk bisa melanjutkan ke tahap pemesanan dan untuk menikmati diskon yang ada.

\section{Fitur Special Discount}

Fitur ini berisi tentang produk-produk yang ditawarkan khusus untuk membership dengan harga diskon. Dan produk yang ditawarkan tersebut disesuaikan dengan event-event yang sedang berlangsung sesuai keinginan pemilik.

\section{Fitur Best Seller}

Di dalam fitur ini, pelanggan dapat mencari produk-produk yang paling banyak terjual, sehingga pelanggan bisa langsung mencari produk-produk sesuai rekomendasi pelanggan lainnya. 


\section{E. Fitur Pengelompokan barang berdasarkan Filter yang dipilih}

Di fitur ini pelanggan dapat memfilter barang sesuai dengan yang diinginkan oleh pelanggan. Bisa sesuai dengan jenis, ataupun harga.

\section{F. Fitur Realtime Customer Service Chat}

Fitur ini memudahkan pelanggan untuk menanyakan sesuatu pada admin website saat itu juga. Pelanggan dapat langsung berkomunikasi dengan admin melalui chatting dengan memasukkan nama, alamat, dan nomor telepon pelanggan. Fitur Realtime chat menggunakan layanan dari Tawk.To.

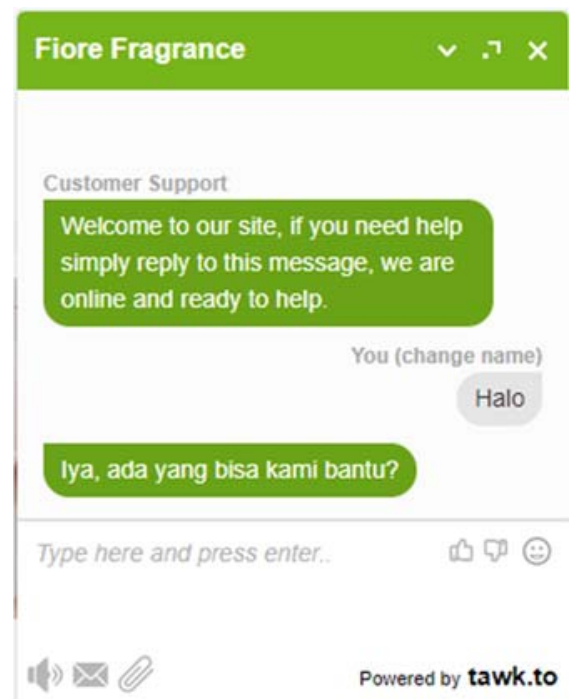

Gambar. 5. Tampilan realtime customer service chat.

\section{G. Fitur Pembayaran}

Dengan sistem pembayaran yang sudah ditentukan dengan menggunakan sistem transfer, pelanggan akan melakukan transfer dan pelanggan harus memasukkan no transfer beserta no pesanan ke dalam form website pembayaran, agar pengiriman barang dapat segera dikerjakan.

\section{H. Fitur Table Décor}

Fitur ini dimana pelanggan dapat memilih dekorasi meja untuk event-event yang sedang berlangsung. Pelanggan dapat memilih jenis-jenis dekorasi dari jenis event yang berlangsung.

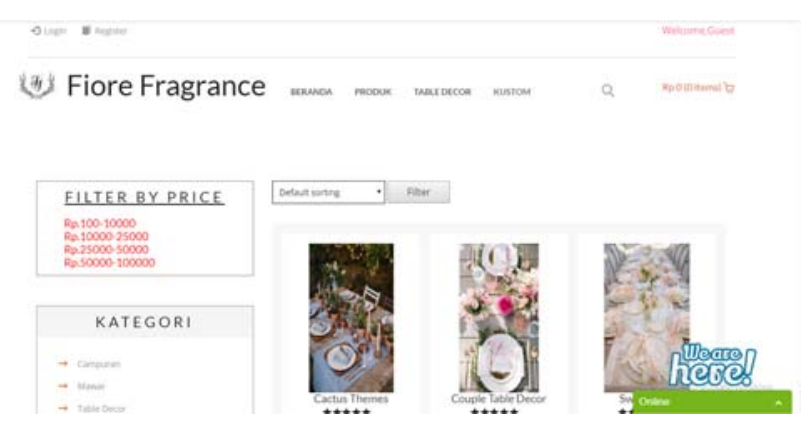

Gambar. 6. Tampilan halaman produk table decor.

\section{Fitur Kustom Bunga Realtime}

Fitur ini digunakan khusus bagi pelanggan yang suka dengan merangkai sendiri bunga apa yang diinginkan sesuai dengan kreasi dari pelanggan. Pelanggan dapat merangkai dengan bebas dengan bunga apapun yang mereka inginkan dan dengan bentuk apapun yang diinginkan oleh pelanggan. Pelanggan bisa secara realtime mendesain bentuk rangkaian bunga yang diinginkan dengan cara drag $\&$ drop pada gambar bunga yang diinginkan. Sehingga pelanggan bisa melihat dahulu bentuk bunga rangkaiannya sendiri sebelum memesan. Berikut adalah contoh halaman kustomisasi bunga.

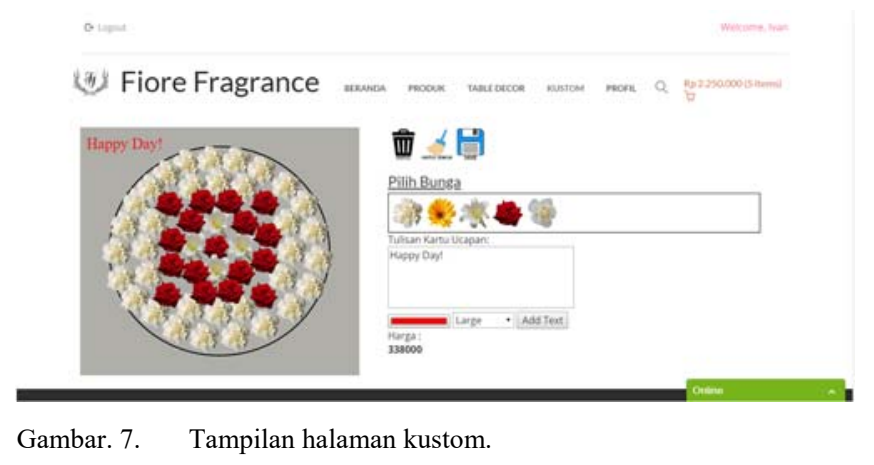

\section{J. Fitur Penambahan Produk}

Fitur ini membantu admin dalam menambahkan suatu produk-produk baru, bisa berupa tanaman, bunga, ataupun barang dekorasi di dalam bagian back-end.

\section{K. Fitur Stok Produk}

Dengan fitur tersebut pelanggan dapat mengetahui secara langsung stok dari produk/bunga yang ingin dipesan. Untuk stok yang sedang habis, maka produk tersebut tidak dapat dipesan.

\section{Fitur Pengiriman}

Untuk fitur pengiriman, kurir yang digunakan merupakan bersifat personal, tanpa menggunakan jasa yang ada, itu dikarenakan untuk menjaga bentuk dan kesegaran bunga yang dipesan. Pelanggan dapat memilih mengambil sendiri produk tersebut pada toko bunga tersebut, atau pelanggan juga dapat meminta dikirimkan dengan harga yang ditentukan oleh toko bunga tersebut.

\section{Fitur Report}

Pemilik bisa memanfaatkan fitur tersebut untuk melihat apa yang sedang terjadi dengan tokonya. Pemilik dapat melihat laporan dari laba/rugi, laporan biaya pengeluaran, laporan penjualan produk website tersebut selama satu bulan, juga ada laporan untuk melihat history dari setiap pelanggan yang melakukan transaksi di dalam website tersebut.

\section{N. Fitur Rating Produk}

Pelanggan juga dapat memberikan rating pada website ini sesaat setelah pelanggan selesai melakukan transaksi di dalam website. Jadi pelanggan juga dapat melihat rating dari setiap produk yang ada dan memastikan kualitas dari produk tersebut baik. 


\section{UJi COBA WeBsite FIORE FraGRANCE}

Uji coba meliputi uji coba yang dilakukan terhadap program website yang telah dibuat dan uji coba yang dilakukan melalui kuesioner yang ditujukan kepada 20 responden. Hasil dari uji coba ini diperoleh dari kuesioner yang disebar untuk mengetahui pendapat, penilaian dan tingkat keberhasilan dari website toko bunga ini. Semua yang tertulis di dalam ini adalah hasil percobaan yang sebenarnya dan tidak dibuat-buat. Berikut penjelasan uji coba yang sudah dilakukan terhadap website toko bunga ini.

\begin{tabular}{|c|c|c|c|c|c|c|}
\hline \multicolumn{7}{|c|}{$\begin{array}{c}\text { TABEL I } \\
\text { UJI COBA } \\
\end{array}$} \\
\hline No & Pertanyaan & 1 & 2 & 3 & 4 & 5 \\
\hline 1 & $\begin{array}{l}\text { Apakah } \\
\text { mudah } \\
\text { melakukan } \\
\text { pemesanan } \\
\text { bunga } \\
\text { dalam } \\
\text { website? }\end{array}$ & $\begin{array}{c}0 \% \\
\text { Tidak }\end{array}$ & $\begin{array}{c}100 \% \\
Y a\end{array}$ & & & \\
\hline 2 & $\begin{array}{l}\text { Kemudahan } \\
\text { dalam } \\
\text { melakukan } \\
\text { transaksi }\end{array}$ & $\begin{array}{c}0 \% \\
\text { Sangat } \\
\text { Susah }\end{array}$ & $\begin{array}{c}0 \% \\
\text { Susah }\end{array}$ & $\begin{array}{c}0 \% \\
\text { Biasa } \\
\text { Saja }\end{array}$ & $\begin{array}{r}70.8 \% \\
\text { Mudah }\end{array}$ & $\begin{array}{l}29.2 \% \\
\text { Sangat } \\
\text { Mudah }\end{array}$ \\
\hline 3 & $\begin{array}{l}\text { Kemudahan } \\
\text { dalam } \\
\text { melakukan } \\
\text { kustomisasi }\end{array}$ & $\begin{array}{c}0 \% \\
\text { Sangat } \\
\text { Susah }\end{array}$ & $\begin{array}{c}0 \% \\
\text { Susah }\end{array}$ & $\begin{array}{c}12.5 \% \\
\text { Biasa } \\
\text { Saja }\end{array}$ & $\begin{array}{l}54.2 \% \\
\text { Mudah }\end{array}$ & $\begin{array}{l}33.3 \% \\
\text { Sangat } \\
\text { Mudah }\end{array}$ \\
\hline 4 & $\begin{array}{l}\text { Tampilan } \\
\text { desain } \\
\text { website }\end{array}$ & $\begin{array}{l}0 \% \\
\text { Tidak } \\
\text { Mena- } \\
\text { rik }\end{array}$ & $\begin{array}{l}4.2 \% \\
\mathrm{Ku}- \\
\text { rang } \\
\text { Mena- } \\
\text { rik }\end{array}$ & $\begin{array}{c}16.7 \% \\
\text { Biasa } \\
\text { Saja }\end{array}$ & $\begin{array}{c}70.8 \% \\
\text { Mena- } \\
\text { rik }\end{array}$ & $\begin{array}{c}8.3 \% \\
\text { Sangat } \\
\text { Mena- } \\
\text { rik }\end{array}$ \\
\hline 5 & $\begin{array}{l}\text { Kepuasan } \\
\text { dalam } \\
\text { mengguna- } \\
\text { kan website }\end{array}$ & $\begin{array}{l}4.2 \% \\
\text { Tidak } \\
\text { Puas }\end{array}$ & $\begin{array}{l}4.8 \% \\
\mathrm{Ku}- \\
\text { rang } \\
\text { Puas }\end{array}$ & $\begin{array}{c}8.3 \% \\
\text { Biasa } \\
\text { Saja }\end{array}$ & $\begin{array}{c}66.7 \% \\
\text { Puas }\end{array}$ & $\begin{array}{c}20.8 \% \\
\text { Sangat } \\
\text { Puas }\end{array}$ \\
\hline 6 & $\begin{array}{l}\text { Apakah } \\
\text { pemilik } \\
\text { toko merasa } \\
\text { website ini } \\
\text { membantu } \\
\text { jalannya } \\
\text { usaha? }\end{array}$ & $\begin{array}{c}0 \% \\
\text { Sangat } \\
\text { Tidak } \\
\text { Mem- } \\
\text { bantu }\end{array}$ & $\begin{array}{c}0 \% \\
\text { Tidak } \\
\text { Mem- } \\
\text { bantu }\end{array}$ & $\begin{array}{c}18.2 \% \\
\text { Biasa } \\
\text { Saja }\end{array}$ & $\begin{array}{l}63.6 \% \\
\text { Cukup } \\
\text { Mem- } \\
\text { bantu }\end{array}$ & $\begin{array}{l}18.2 \% \\
\text { Sangat } \\
\text { Mem- } \\
\text { bantu }\end{array}$ \\
\hline
\end{tabular}

Dari hasil kuesioner yang dijabarkan pada tabel di atas, pada pertanyaan pertama, dapat dilihat bahwa melakukan pemesanan dalam website ini sangatlah mudah. Kemudian pada pertanyaan kedua dapat diketahui bahwa melakukan transaksi di dalam website ini cukuplah mudah.

Dalam pertanyaan ketiga dapat disimpulkan bahwa pelanggan mudah dalam melakukan kustomisasi. Tampilan dari website ini juga tergolong menarik dan responden merasa puas dalam menggunakan website ini. Dari hasil kuisioner, diketahui bahwa pemilik toko merasa cukup terbantu untuk menjalankan usahanya dengan menggunakan website ini.

\section{KESIMPULAN}

Pada subbab ini akan dijelaskan mengenai beberapa kesimpulan yang didapat dari pembuatan website toko bunga ini. Kesimpulan didapatkan berdasarkan perkembangan selama proses pembuatan website toko bunga ini.Kesimpulan-kesimpulan yang didapat antara lain:

1. Pemilik toko merasa terbantu untuk mengatur usahanya dengan adanya fitur-fitur yang disediakan oleh website ini, seperti master produk, setup produk terbaik, dan spesial diskon, dan juga melihat laporan transaksi.

2. Pelanggan dapat melakukan transaksi di dalam website ini dengan mudah dari langkah awal pemesanan, pengaturan pengiriman, sampai melakukan pembayaran menggunakan transfer dan mengunggah bukti transfer.

3. Pelanggan dapat melakukan kustomisasi buket bunga atau papan bunga dengan desain sesuai keinginan mereka dengan mudah.

\section{UCAPAN TERIMA KASIH / ACKNOLEDGMENT}

Penulis mengucapkan rasa syukur kepada Tuhan Yesus Kristus, karena berkat dan kasih-Nya sehingga penulis dapat menyelesaikannya tepat waktu. Penulis juga mengucapkan terima kasih kepada keluarga, para dosen, dan teman-teman yang selalu mendukung dan membantu memberikan pengarahan kepada penulis.

\section{DAFTAR PUSTAKA}

[1] Alatas, Husein. 2013. "Responsive Web Design dengan PHP \& Bootstrap." Yogyakarta: Lokomedia.

[2] Andre. (2014). "Tutorial Belajar JavaScript Part 1:Pengertian dan Fungsi JavaScript dalam Pemrograman Web." [Online].Available: https://www.duniailkom.com/tutorial-belajar-javascript-pengertiandan-fungsi-javascript-dalam-pemograman-web/.

[3] Castro Elizabeth, Bruce Hyslop. "HTML5: Visual QuickStart Guide." 2011. Peachpit Press.

[4] Cylinder Carly. "The Flower Chef: A Modern Guide to Do-It-Yourself Floral Arrangements.” 2016. Grand Central Publishing.

[5] DeLone W.H.s, Ephraim R. McLean. "The DeLone and McLean Model of Information System Success: A Ten-Year Update.” 2003. WH DELONE.

[6] FabricJs. (2016). "Fabric.js.” [Online].Available: http://fabricjs.com/.

[7] IndoSite. (2017). "Pengertian MySQL." [Online].Available: https://www.indosite.com/pengertian-mysql/.

[8] Miller, L. "The Practitioner's Guide to User Experience Design.” New York: General Assembly, 2015.

[9] R.H.M Sianipar. 2015. "HTML5 \& CSS3: Belajar dari Kasis." Bandung: Penerbit Informatika 